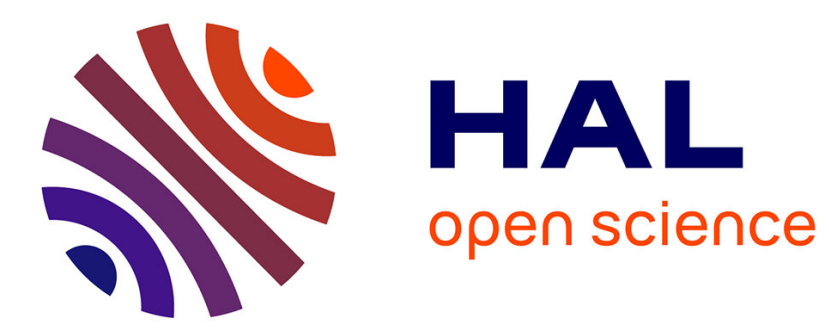

\title{
On Ferrites. Theory and Practise
}

E. Bertaut

\section{- To cite this version:}

E. Bertaut. On Ferrites. Theory and Practise. Journal de Physique IV Proceedings, 1997, 07 (C1), pp.C1-11-C1-26. 10.1051/jp4:1997101 . jpa-00254711

\section{HAL Id: jpa-00254711 https://hal.science/jpa-00254711}

Submitted on 1 Jan 1997

HAL is a multi-disciplinary open access archive for the deposit and dissemination of scientific research documents, whether they are published or not. The documents may come from teaching and research institutions in France or abroad, or from public or private research centers.
L'archive ouverte pluridisciplinaire HAL, est destinée au dépôt et à la diffusion de documents scientifiques de niveau recherche, publiés ou non, émanant des établissements d'enseignement et de recherche français ou étrangers, des laboratoires publics ou privés. 


\title{
On Ferrites. Theory and Practise
}

\author{
E.F. Bertaut
}

C.N.R.S., Laboratoire de Cristallographie, 25 avenue des Martyrs, BP. 166, 38042 Grenoble cedex 09, France

Prologue: I feel rather proud to talk here for two reasons, first to comment on Professor Neel's message and second because I got my diploma of chemical engineering and of master in math, physics, chemistry, here in Bordeaux.

Néel's message : Néel published his famous paper "Propriétés Magnétiques des Ferrites : Ferrimagnétisme et Antiferromagnétisme" in Les Annales de Physique (1948).

It is true that he has coined there in 1948 the definition of ferrimagnetism. However, Néel's formula, alluded to in his message, was born much earlier, in fact in 1932 where it appears as formula (83) in his thesis work. In view of its historical importance, it is printed here with the original notations and with the proof, given in the thesis.

Néel considers two magnetic species $A$ and $B$ of magnetic moments $\mu_{A}$ and $\mu_{B}$, Curie constants $C_{A}$ and $C_{B}$, and in proportions $P$ and $Q(1)$. The total moment is $\mu(2)$. Néel postulates the existence of two local molecular fields $h_{A}$ (3) and hB (4) depending linearly on $\mu_{\mathrm{A}}$ and $\mu_{\mathrm{B}}$. Here $\mathrm{n}_{\mathrm{AA}}, \mathrm{n}_{\mathrm{AB}}=\mathrm{n}_{\mathrm{BA}}, \mathrm{n}_{\mathrm{BB}}$ are interaction coefficients which Néel abridges a, b, c, respectively (5). One has not the Curie law $\mu=\mathrm{CH} / \mathrm{T}$ where $\mathrm{H}$ is the applied field but the relations (6) (7) where the local molecular fields $h_{A}$ and $h_{B}$ are added to the applied field. The result of the elimination of $h_{A}, h_{B}, \mu_{A}$ and $\mu_{B}$ in the equations written here is the famous formula (8) which relates the total moment $\mu$ to the applied field $\mathrm{H}$.

The magnetic susceptibility $\chi$ is the ratio M/H. It is easily seen that the inverse susceptibility has the form (9) where the last term is Néel's hyperbola.

$$
\begin{gathered}
\mathrm{P}+\mathrm{Q}=1 \\
\mu=\mu_{\mathrm{A}}+\mu_{\mathrm{B}} \\
\mathrm{h}_{\mathrm{A}}=\mathrm{n}_{\mathrm{AA}} \mu_{\mathrm{A}}+\mathrm{n}_{\mathrm{AB}} \mu_{\mathrm{B}} \\
\mathrm{h}_{\mathrm{B}}=\mathrm{n}_{\mathrm{BA}} \mu_{\mathrm{A}}+\mathrm{n}_{\mathrm{BB}} \mu_{\mathrm{B}} \\
\mathrm{a}=\mathrm{n}_{\mathrm{AA}} ; \mathrm{b}=\mathrm{n}_{\mathrm{AB}}=\mathrm{n}_{\mathrm{BA}}, \mathrm{c}=\mathrm{n}_{\mathrm{BB}} \\
\mu_{\mathrm{A}}=\mathrm{PC}_{\mathrm{A}}\left(\mathrm{H}+\mathrm{h}_{\mathrm{A}}\right) / \mathrm{T} \\
\mu_{\mathrm{B}}=\mathrm{QC}_{\mathrm{B}}\left(\mathrm{H}+\mathrm{h}_{\mathrm{B}}\right) / \mathrm{T} \\
\mathrm{Neel}^{\prime} \mathrm{s} \text { formula }(\mathbf{8 3})(\mathbf{1 9 3 2}) \\
\frac{\mathrm{T}\left(\mathrm{PC}_{\mathrm{A}}+\mathrm{QC}_{\mathrm{B}}\right)-\mathrm{PQC} \mathrm{A} \mathrm{C}_{\mathrm{B}}(\mathrm{a}+\mathrm{c}-2 \mathrm{~b})}{\mathrm{T}\left(\mathrm{PC}_{\mathrm{A}} \mathrm{a}+\mathrm{QC}_{\mathrm{B}} \mathrm{c}\right)+\mathrm{PQC}_{\mathrm{A}} \mathrm{C}_{\mathrm{B}}\left(\mathrm{ac}-\mathrm{b}^{2}\right)} \mathrm{H}
\end{gathered}
$$




$$
\begin{gathered}
\frac{1}{\chi}=\frac{\mathrm{H}}{\mu}=\frac{\mathrm{T}}{\mathrm{C}^{\prime}}+\frac{1}{\chi_{0}}-\frac{\sigma}{\mathrm{T}-\Theta} \\
\mathrm{C}^{\prime}=\mathrm{PC}_{\mathrm{A}}+\mathrm{QC}_{\mathrm{B}}
\end{gathered}
$$

Although Néel knew about Kramer's work (1934) on negative super-exchange interactions $\left(n_{A B}<0\right)$ he remained silent because at that time the linearity of the $1 / \chi$ plot versus $T$ was a dogma and it was a heresy to fight against the unique molecular field (1906) of P. Weiss who was the Director of the laboratory. Verwey and Heilmann in (1947) gave Néel the key for his theory of ferrimagnetism. They found $\mathrm{Cd} \mathrm{Fe}_{2} \mathrm{O}_{4}$ to be a "normal" spinel with $\mathrm{Cd}^{2+}$ in a tetrahedral and $\mathrm{Fe}^{3+}$ in a octahedral oxygen environment. They called $\mathrm{Mg} \mathrm{Fe}_{2} \mathrm{O}_{4}$ an "inverse" spinel with $\mathrm{Mg}^{2+}$ being in an octahedron. In the usual notation the formulae would be written $\left(\mathrm{Cd}^{2+}\right)\left[\mathrm{Fe}_{2}^{3+}\right] \mathrm{O}_{4}$ and $\left(\mathrm{Fe}^{3+}\right)\left[\mathrm{Mg}^{2+} \mathrm{Fe}^{3+}\right] \mathrm{O}_{4}$. Note that Verwey is also the father of the "Verwey transition" in magnetite $\mathrm{Fe}_{3} \mathrm{O}_{4}$ where $\mathrm{Fe}^{2+}$ and $\mathrm{Fe}^{3+}$ order in the octahedral positions at $113^{\circ} \mathrm{K}$ with a discontinuity in the conductivity.

I shall now show you the similarity of formula (83) of Néel's thesis and the formula (13) mentioned in his message.

Call $\lambda$ and $\mu$ the proportions of $\mathrm{Fe}^{3+}$ on $\mathrm{A}$ - and $\mathrm{B}$ - sites respectively $\mathrm{Mg} \mathrm{Fe} 2 \mathrm{O}_{4}$ for instance; $\lambda$ and $\mu$ will replace $\mathrm{P}$ and $Q$ respectively. One has here $C_{A}=C_{B}=C$. The total magnetisation is written $J$ instead of $\mu$; also in the demonstration of (13) $\lambda \mathrm{J}_{\mathrm{a}}$ and $\mu \mathrm{J}_{\mathrm{b}}$ stand for $\mu_{\mathrm{A}}$ and $\mu_{\mathrm{B}}$ (11). The interaction coefficients $n_{A A}$, nBB and $n_{A B}$ are denoted by $n \alpha$, n $\beta$ and $\mathrm{n} \varepsilon(12)$.

Thus except for minor differences in the notations the equations (83) and (13) of the message are identical.

$$
\begin{gathered}
\mu_{\mathrm{A}}=\lambda \mathrm{J}_{\mathrm{a}}, \mu_{\mathrm{B}}=\mu \mathrm{J}_{\mathrm{b}} \\
\mathrm{n}_{\mathrm{AA}}=\mathrm{n} \alpha ; \mathrm{n}_{\mathrm{BB}}=\mathrm{n} \beta ; \mathrm{n}_{\mathrm{AB}}=\mathrm{n} \varepsilon \\
\text { with } \mathrm{n}>0, \varepsilon=-1
\end{gathered}
$$

Néel's formula (13) Annales (1948) is

$$
J=C \frac{T-n C \lambda \mu(2+\alpha \beta)}{T^{2}-n C T(\lambda \alpha+\mu \beta)+n^{2} C^{2} \lambda \mu(\alpha \beta-1)} H
$$

Néels hyperbola ( 9 ) is characterized by a set of three constants $\chi_{0}, \sigma, \varnothing$ wherefrom one can deduce the three interactioncoefficients $n_{A A}, n_{A B}, n_{B B}$ (see Néel 1948 and textbooks). In fact, normal and inverse spinels are limiting cases of the general formula

$$
\left(\mathrm{Fe}_{\mathrm{p}}^{3+} \mathrm{M}_{1-\mathrm{p}}^{2+}\right)\left[\mathrm{Fe}_{2-\mathrm{p}}^{3+} \mathrm{M}_{\mathrm{p}}^{2+}\right] \mathrm{O}_{4}
$$

for $\mathrm{p}=0$ and for $\mathrm{p}=1$ respectively, so that one has to do with a fourth variate, the "degree of inversion", represented by $\mathrm{p}$. Néel knew already in 1948 that $p$ depended on temperature and thus on the thermal history of the sample.

To measure $\mathrm{p}$ versus $\mathrm{T}$ in copper ferrite, for instance, from $\mathrm{X}$ ray intensities seems to be a difficult task because $\mathrm{Fe}^{3+}$ and $\mathrm{Cu}^{2+}$ have nearly the same diffusing power. I could show that by using "anomalous dispersion", say a radiation near to the absorption ddge $\mathrm{K} \alpha$ of $\mathrm{Fe}$ one can increase the constrast between $\mathrm{Fe}$ and $\mathrm{Cu}$ and get reliable values of $\mathrm{p}$ (Bertaut 1950).

Nowadays one can certainly do better by approaching the absorption edge at will with the continuous spectrum of synchrotron radiation. 
Of course the difficulties of the degree of inversion do not exist in the YIG, the yttrium iron garnet which represents the case of "pure ferrimagnetism" with only $\mathrm{Fe}^{3+}$ ions present. Here the inverse susceptibility (9) is explicitly (Aléonard, Pauthenet, Barbier, 1956)

$$
\frac{1}{\chi}=\frac{T}{50}+30,5-\frac{990}{T-570}
$$

The interaction coefficients are given there as

$$
\mathrm{n}_{\mathrm{aa}}=-351.9, \quad \mathrm{n}_{\mathrm{dd}}=-210.5, \quad \mathrm{n}_{\mathrm{ad}}=-742
$$

The lower indices $\mathrm{a}$ and $\mathrm{d}$ characterize the octahedral sites 16a) and tetrahedral sites $24 \mathrm{~d}$ ) respectively in $(\mathrm{Fe})_{3}[\mathrm{Fe}]_{2} \mathrm{Y}_{3} \mathrm{O}_{12}$ (YIG).

The exchange integrales, expressed in degrees $\mathrm{K}$, are given in the same sequence as $-8.3,-15.1$ and -35.0 by Smart (1963), and $-6.45,-12.05$ and -30.4 according to Srivastava et al. (1981). Here, different temperature corrections have been used.

\section{ON BINARY SULFIDES}

I do not resist the temptation of citing our contribution to ferri- and antiferro-magnetism in the field of sulfides. Here, crystallography solved « the enigma posed by pyrrhotite $\mathrm{Fe}_{7} \mathrm{~S}_{3}$, a ferromagnetic compound which had long been studied by $P$. Weiss $(1899,1905$ and 1929) which has a weak saturation moment of $3 \mu \mathrm{B}$ whereas on the basis of its formula a value almost ten times as large had been expected » (Néel, 1971).

Indeed $\mathrm{Fe}_{7} \mathrm{~S}_{8}$ was the first structure in cristallography containing ordered vacancies (Bertaut 1952, 1953); its ferrimagnetism is due to the alternation along the c-axis of two kinds of iron planes of opposite spin directions, full iron planes and planes with ordered iron vacancies (fig. 1). The Néel temperature $T_{\mathrm{N}}=320^{\circ} \mathrm{C}$ coincides with the vacancy disorder.

We continue with sulfides FeS. While there is only one oxide $\mathrm{FeO}$, there are at least three FeS families.

Mackinawite is a mineral, but it is easily prepared by the action of $\mathrm{H}_{2} \mathrm{~S}$ on a suspension of iron powder in water. It is tetragonal: $a=3.678 \mathrm{~A}^{\circ}, c=5.038 \mathrm{~A}^{\circ}$, space group $\mathrm{P} 4 / \mathrm{nmm} ; \mathrm{Fe}$ is in the special position $2 \mathrm{a}: 000 ; 1 / 2,1 / 2,0$. The distance $\mathrm{Fe}-\mathrm{S}$ in the $\mathrm{FeS}_{4}$ tetrahedron is $2.23 \mathrm{~A}^{\circ}$, say shorter than the sum $\Sigma=2.28 \mathrm{~A}^{\circ}$ of the covalent radii $\mathrm{r}_{\text {cov }}(\mathrm{Fe})=1.22 \mathrm{~A}^{\circ}$, $\mathbf{r}_{\text {cor }}(\mathrm{S})=1.04 \mathrm{~A}^{\circ}$.

No magnetic ordering, no paramagnetic background, is detected by neutron diffraction down to $4.2 \mathrm{~K}$. The unique line of the Mössbauer spectrum confirms the absence of magnetic order down to $1.7 \mathrm{~K}$ (Bertaut et al. (1965)). Thus we conclude that tetragonal FeS is a diamagnetic semiconductror with covalent bonding due probably to a d's hybrisisation. Mackinawite is metastable and transforms irreversibly under heating to the hexagonal forms.

FeS blende, space group F43m, $a=5.42 \mathrm{~A}^{\circ}$ has been prepared by attacking a steel wire in a water solution of $\mathrm{H}_{2} \mathrm{~S}$ at room temperature. At the same time appear the impurity phases, wackinawite and troilite. The Néel temperature is $T_{\mathrm{N}}=234 \mathrm{~K}$. The transition cubic $\rightarrow$ orthorhombic is first order. This is seen by the discontinuity of the hyperfine field (Wintenberger et al. (1978a)) which jumps from $100 \mathrm{kOe}$ to zero at $T_{\mathrm{N}}$, but also by the coexistence of the two phases: when cooling the sample from high temperature, an orthorhombic phase appears at $238 \mathrm{~K}$ and the cubic phase disappears at $230 \mathrm{~K}$. The parameters of the orthorhombic phase, space group $\mathrm{F} 222$, are $\mathrm{a}=5.54 \mathrm{~A}^{\circ}, \mathrm{B}=5.48 \mathrm{~A}^{\circ}, \mathrm{C}=5.195 \mathrm{~A}^{\circ}$ at 81 $\mathrm{K}$.

Mössbauer effect (Wintenberger et al. (1978a)) and neutron diffraction (Wintenberger et al. (1978b)) show that ferromagnetic planes are coupled antiferromagnetically along $\mathrm{c}$, the spin drirection being along a. The magnetic space group is $\mathrm{F}_{\mathrm{c}} 22^{\prime} 2^{\prime}$.

No transition blende $\rightarrow$ warwickite, blende $\rightarrow$ troilite has been reported.

The heaxagonal form FeS, called troilite, has features which are suprising, at least for me (Bertaut, 1956, 1957). In ionic structures, the cation generally occupies special positions. In troilite, Fe occupies a general position while $S$ is distributed over three different special positions. The unit cell is rather large wuith $A=a \sqrt{3}, C=2 c$ where a and $c$ are the parameters of the classical NiAs type. The space group in non centro-symmetric P62c. I had the pleasure to learn that my structure proposal was checked again and refined by H.T. Evans (1970) on a lunar sample of troilite. Between 138 and $150^{\circ} \mathrm{C}$, FeS triolite transforms in a first order transition to an orthorhombic structure of MnP type Pnma (Putnis 1974, King et Prewit 1982, Töpel-Schadt et al. 1982). The heat of transformation, the so-called $\alpha$-transition (Haraldsen, 1941) is rather high, about $550 \mathrm{cal} / \mathrm{mol}$ (Hirone 1954). A second order transition takes place above $220^{\circ} \mathrm{C}$, giving rise to the nickel arsenide a,c-phase of space group $P 6_{3} / \mathrm{mmc}$ where $\mathrm{T}_{\mathrm{v}}=600 \mathrm{~K}$.

The reactions: troilite $\rightarrow \mathrm{MnP}$ type $\rightarrow$ NiAs type are reversible (Töpel-Schadt et al. 1982) and I ask once more about the dielectric properties of FeS; the antiferromagnetic semi-conductor troilite, is it ferroelectric ?

It is remarkable that the magnetic interaction $\mathrm{Fe}_{2+}-\mathrm{S}-\mathrm{Fe}_{2+}$ in blende and triolite is stronger than in $\mathrm{Fe}^{2+}-\mathrm{O}-\mathrm{Fe}^{2+}$ $\left(\mathrm{T}_{\mathrm{N}}(\mathrm{FeO})=190 \mathrm{~K}\right)$. However the interaction $\mathrm{Fe}^{3+}-\mathrm{S}-\mathrm{Fe}^{3+}$ is much weaker than $\mathrm{Fe}^{3+}-\mathrm{O}-\mathrm{Fe}^{3+}$,

The inverse spinel $\mathrm{Fe}_{3} \mathrm{~S}_{4}$ exists, but no Verwey transition takes place (Coey et al. 1970). Goodenough has discussed in detail the electronic structure of triolite (1962) and more generally iron sulfides (1982) with respect to the nature, itimerant or localized, of their electrons. 


\section{REPRESENTATION ANALYSIS}

The magnetic energy is given by (14) in terms of interaction coefficients and magnetizations of the sublattices A and B or by the Van Vleck-Heisenberg hamiltonian of order two (15) in terms of exchange integrals and scalar spin products (Néel 1948, part IV). These expressions have proved useful in the many transition metal compounds where collinear structures are frequent. They are still applicable to helical situations.

$$
\begin{aligned}
& \mathscr{H}=-\frac{1}{2}\left(\mathrm{n}_{\mathrm{AA}} \mu_{\mathrm{A}}^{2}+\mathrm{n}_{\mathrm{BB}} \mu_{\mathrm{B}}^{2}+2 \mathrm{n}_{\mathrm{AB}} \mu_{A} \mu_{B}\right) \\
& \mathscr{H}=-2 \sum_{\mathrm{S}} J_{\mathrm{iJ}} \overrightarrow{\mathrm{S}}_{\mathrm{i}} \overrightarrow{\mathrm{S}}_{\mathrm{J}}
\end{aligned}
$$

The situation has changed with the advent of neutron scattering and with low temperature studies of compounds with $f$ electrons, say with rare earths and actinides where the orbital moments play an important role. It is well known that in iron rare earth compounds, iron orders first and the rare earth behaves like a paramagnetic ion in the molecular field of the iron lattice. Lowering the temperature the rare earth ion discovers its environment and the coupling rare earth-iron changes the structure to non collinear, say "canted" situations. The tool we have created for non collinear structures is called "Representation Analysis" and the essential role is plaid by "Basis Vectors of Irreducible Representations". This mathematical terminology sounds frightening. My intention is not to give a lecture on group theory, but to tell you in an every day language what representation analysis is for and how it works. No differential equations, no relativity theory come in ; no quantum mechanics is required. What you have to know is how a symmetry operation acts on a magnetic moment, say on an axial vector. As an example let us choose the compounds $\mathrm{A} \mathrm{B} \mathrm{O}_{3}$ in the space group $\mathrm{P}$ b n m $-\mathrm{D}_{2 \mathrm{~h}}^{16}$ where $\mathrm{A}$ stands for Fe and $\mathrm{B}$ for the rare earth in the deformed perovskite.

\section{Basis vectors}

The A-moments are in four symmetry centers, numbered from 1 to 4 . I shall cite now some of the attractive properties of "basis vectors" of the A - moments.

"A basis vector is the portrait of a magnetic mode". The basis vector $\mathrm{G}_{\mathrm{X}}$

$$
G_{X}=+S_{1 x}-S_{2 x}+S_{3 x}-S_{4 x}
$$

represents an antiferromagnetic mode say a succession +-+ - of the magnetic moments along the $\mathrm{x}$ - axis.

The basis vector $\mathrm{Fz}$

$$
F_{z}=+S_{1 z}+S_{2 z}+S_{3 z}+S_{4 z}
$$

represents a ferromagnetic mode along the $z$ - axis.

"A basis vector $G_{X}$ under a symmetry operation transforms into itself, $+G_{X}$, or into its opposite $-G_{X}$ "

The symmetry operations listed here (table 1 ) are the screw axes $21 x$ and $21 y$, and the inversion center $\overline{1}$. I leave it up to the reader to explain while under the operation $\overline{1}$ one has always the + sign.

The basis vectors which we deal with are the $\mathrm{x}, \mathrm{y}, \mathrm{z}$ components of the vectors $\mathbf{F}, \mathbf{G}, \mathbf{C}$, A, defined below :

$$
\begin{aligned}
& F=+S_{1}+S_{2}+S_{3}+S_{4} \\
& G=+S_{1}-S_{2}+S_{3}-S_{4}
\end{aligned}
$$




$$
\begin{aligned}
& c=+s_{1}+s_{2}-s_{3}-s_{4} \\
& A=+s_{1}-s_{2}-s_{3}+s_{4}
\end{aligned}
$$

$\mathrm{G}_{\mathrm{X}}$ and $\mathrm{F}_{\mathrm{Z}}$ stay in the same line $\Gamma_{4}$; "they belong to the same representation $\Gamma_{4}$ " means that they transform in the same way.

A representation like $\Gamma_{4}$ is said "irreducible" when it cannot be made simpler anymore.

\section{Coupling of magnetic modes}

"The product $G_{x} F_{z}$ is invariant in any symmetry operation" means firstly that "an antiferromagnetism along $x$ may be coupled with a ferromagnetism along $z$ " and secondly that "the product $G_{X} F_{z}$ can figure in a hamiltonian".

Such a situation arises in many rare earth ferrites at room temperature : an antiferromagnetic mode $G_{X}$ is seen by neutron diffraction and a week ferromagnetic mode $\mathrm{F}_{\mathrm{Z}}$ appears from elementary magnetic measurements. A glance on table 1 suggests two questions, firstly why $G_{X} F_{Z}$ in $\Gamma_{4}$ and not $F_{X} G_{Z}$, allowed in $\Gamma_{2}$ and secondly can one provoke the situation $F_{X} G_{Z}$ ? The answer is that much "spin reorientations" effectively take place either as a function of temperature or due to the application of an appropriate field. The theory is amply discussed by Yamaguchi (1974).

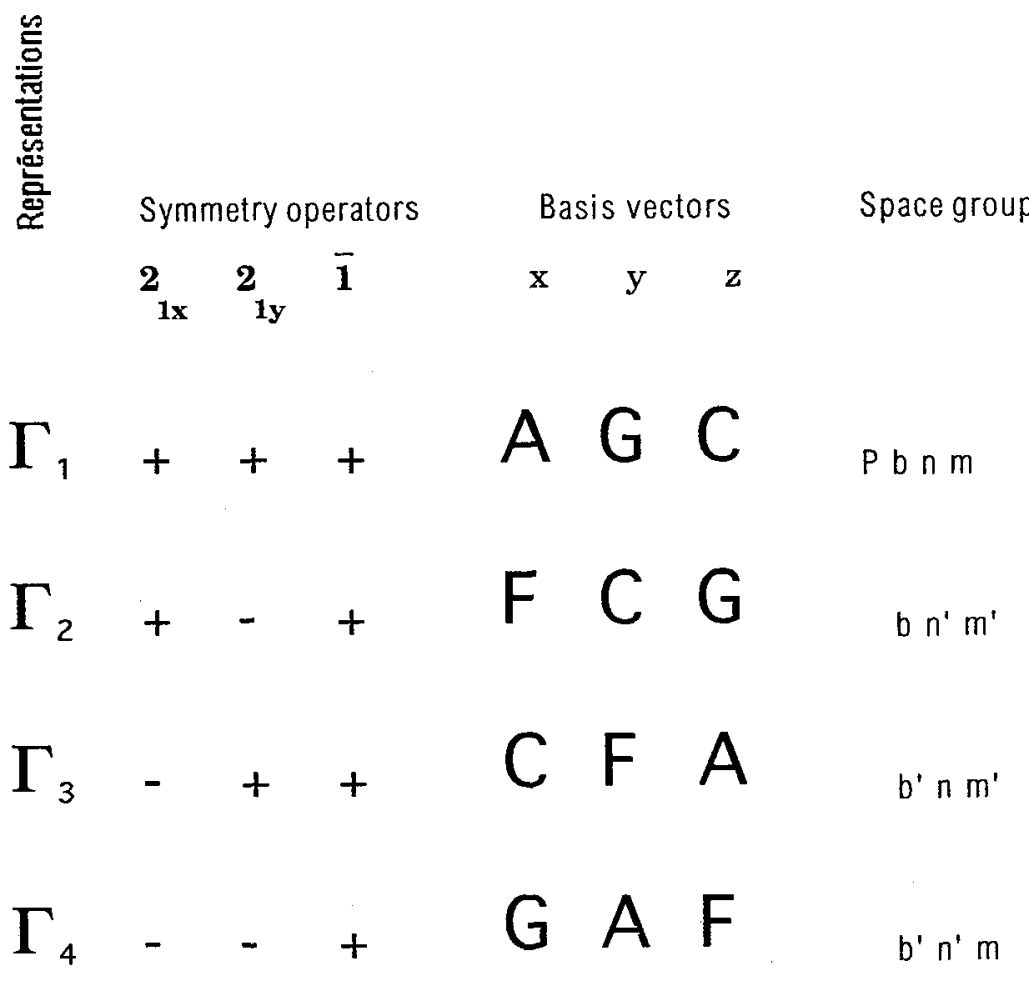

Table 1: Basis vectors of irreducible representations. A-atoms are on the sites:

$$
\frac{1}{2} 00 \text { (1) ; } \frac{1}{2} 0 \frac{1}{2} \text { (2); } 0 \frac{1}{2} \frac{1}{2} \text { (3); } 0 \frac{1}{2} 0 \text { (4). }
$$




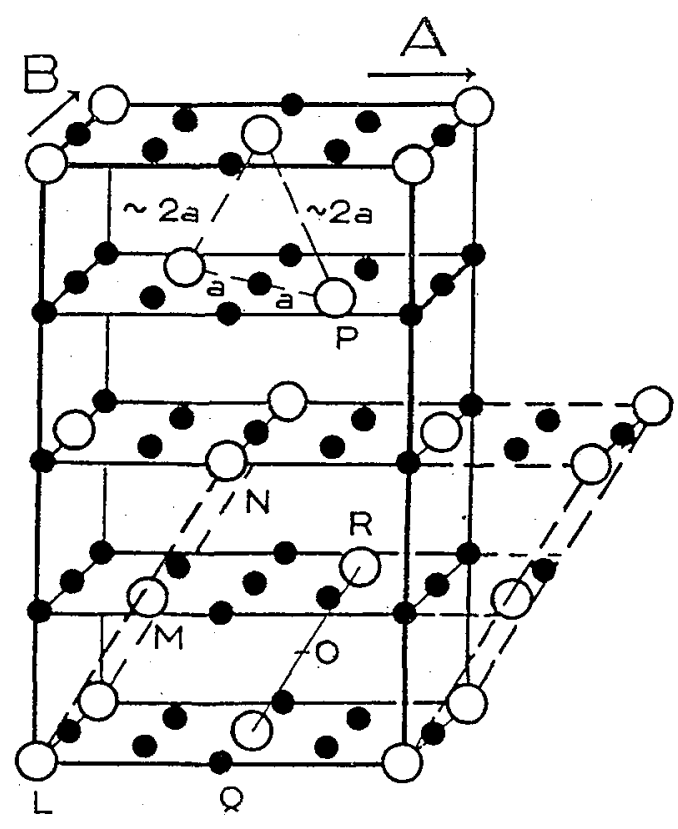

Fig. 1

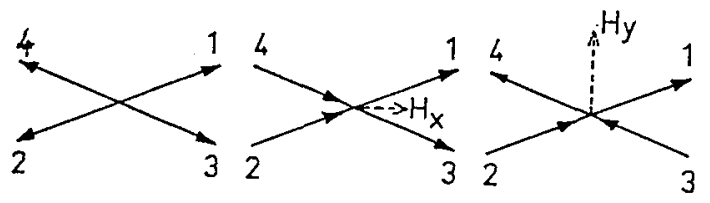

a)

c)

Figure 1: Pyrrhotite $\mathrm{Fe}_{7} \mathrm{~S}_{8}$. Planes of iron (full circles) with ordered vacancies (empty circles). Full planes of iron or sulfur are not shown.

Figure 2 : spin-flip in $\mathrm{TbAlO}_{3}$. a) $\mathrm{G}_{\mathrm{x}} \mathrm{A}_{\mathrm{y}}$; b) $\mathrm{F}_{\mathrm{X}} \mathrm{C}_{\mathrm{y}}$; c) $\mathrm{C}_{\mathrm{x}} \mathrm{F}_{\mathrm{y}}$.

The hamiltonian for the A-atoms has the form (16) where $i$ and $j$ design the numbers 1 to $4, \alpha$ and $\beta$ stand for $x, y, z$ so that one has to discuss 144 terms under the summation. I hope that the reader will appreciate our approach by the basis vectors.

$$
\mathcal{H}=\sum_{i, j} \sum_{\alpha, \beta} A_{i, j}^{\alpha, \beta} S_{\alpha}^{i} S_{\beta}^{j}
$$

The B atoms.- For the construction of Table 2 we use the same designations F,G,C,A as before. There are 8 representations $\Gamma_{\mathrm{j}}$. Our first application will be the metamagnetism in $\mathrm{TbAlO}_{3}$ (Holmes et al. (1968)) which orders at $\mathrm{T}_{\mathrm{N}}=3.8$ $K$, in a configuration $G_{x} A_{y}\left(\Gamma_{5}\right)$. The local anisotropy is supposed so high that the angle $\alpha$ of the spins with the axis $O x$ does not change. Thus when a field $H_{X}$ is applied along the $x$-axis, the moments 1 and 3 will be conserved whilst those of 2 and 4 shall get inverted if the field $\mathrm{H}_{\mathrm{X}}$ exceeds a critical value $\mathrm{H}_{\mathrm{Xcrit}}$ (fig.2). The energy balance is given by

and

$$
\mathrm{W}_{1}=\mathrm{W}_{12}+\mathrm{W}_{34}=2 \mathrm{~W}_{12} \quad \text { before switching }
$$

$$
\mathrm{W}_{2}=-2 \mathrm{~W}_{12}-4 \mathrm{MH}_{\mathrm{x}} \cos \alpha \quad \text { after switching }
$$

where $\mathrm{M}$ is the magnetic moment of the (Ising-like) spins.

The critical field is given by

$$
\mathrm{W}_{1}=\mathrm{W}_{2} \quad \text { say } \mathrm{W}_{12}=-\mathrm{MH}_{\mathrm{x} \text { crit }} \cos \alpha
$$

Consulting the figure 2 and table 2 one has switched the configuration $G_{x} A_{y}\left(\Gamma_{5}\right)$ to $F_{x} C_{y}\left(\Gamma_{2}\right)$ 
Applying the field along $O y$ one finds by the same procedure

$$
\mathrm{W}_{12}=-\mathrm{MH}_{\mathrm{ycrit}} \sin \alpha
$$

where $H_{y c r i t}$ is the critical field along Oy which switches $G_{x} A_{y}\left(\Gamma_{5}\right)$ to $C_{x} F_{y}\left(\Gamma_{3}\right)$ (table 2$)$.

One has

From the plots of Holmes et al. (1968) one extrapolates

$$
\frac{H_{x c r i t}}{H_{\text {ycrit }}}=\operatorname{tg} \alpha
$$

$$
\mathrm{H}_{\mathrm{Xcrit}}=8.5 \mathrm{Kre} \quad \text { and } \quad \mathrm{H}_{\text {ycrit }}=12.5 \mathrm{~K} \propto \quad \text { so that }
$$

$\operatorname{tg} \alpha=0.68$ and $\alpha=34.2^{\circ}$, which is near to $\alpha=34^{\circ}$ as determined directly by neutron diffraction at $1.5 \mathrm{~K}$ on $\mathrm{TbAlO}_{3}$ (Maréschal et al. (1968)).

$$
\begin{aligned}
& 2_{1 x}^{2} \overline{1 y}_{1 y} \quad x \quad y \quad z
\end{aligned}
$$

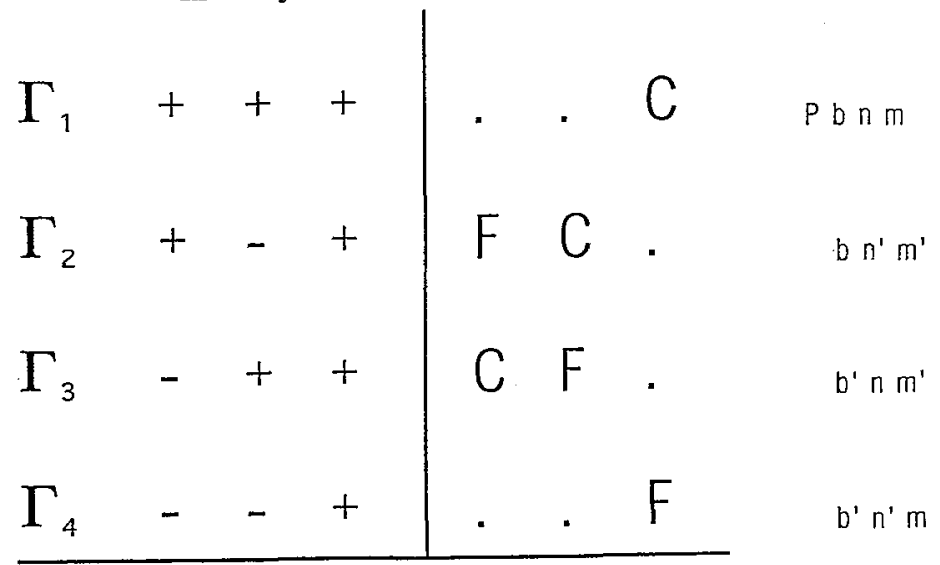

$$
\begin{aligned}
& \Gamma_{5}++-G A b^{\prime} n^{\prime} m \\
& \Gamma_{6}+\ldots+. \quad . \quad \cdot b^{\prime} n m \\
& \Gamma_{7}-+\ldots \quad . \quad 6 n^{\prime} m
\end{aligned}
$$

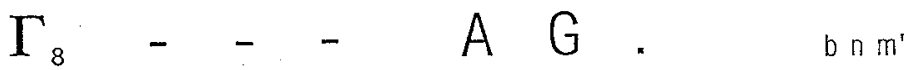

Table 2: Basis vectors of irreducible representations. B-atoms are on the sites:

$$
\begin{aligned}
& x y \frac{1}{4}(1) ; x y \frac{3}{4}(2) ; \frac{1}{2}+x, \frac{1}{2}-y, \frac{3}{4}(3) ; \frac{1}{2}-x, \frac{1}{2}+y, \frac{1}{4} \\
& x=-.18 \quad ; \quad y=.060
\end{aligned}
$$


The simultaneous use of tables 1 and 2 is most rewarding for coupling magnetic modes of $A$ with $B$ atoms.

In $\mathrm{HoCrO}_{3}$ at $\mathrm{T}_{\mathrm{N} 1}=141.3 \mathrm{~K}$, the $\mathrm{Cr}$ - moments order in the $\mathrm{F}_{\mathrm{X}} \mathrm{G}_{\mathrm{Z}}-\left(\Gamma_{2}\right)$ - configuration, the ferromagnetic component being weak, table 1 , and at $\mathrm{T}_{\mathrm{N} 2}=12 \mathrm{~K}$ the rare earth orders to $\mathrm{F}_{\mathrm{x}} \mathrm{C}_{\mathrm{y}}$ in the same representation $\Gamma_{2}$, table 2 (Bertaut et al. 1963). It is remarkable that the same structure has been reported for $\mathrm{HoFeO}_{3}$ (Koehler et al. 1960, cf. Fig. 3). Here we can infer a scalar coupling for the ferromagnetic components $F_{X}(C r)$ and $F_{X}(H o)$, by classical superexchange. Our tabulation tells us that the orthogonality of the components $\mathrm{G}_{\mathrm{z}}(\mathrm{Cr})$ and $\mathrm{C}_{\mathrm{y}}(\mathrm{Ho})$, coupled in $\Gamma_{2}$ is justified by symmetry, but does not tell us the physical reason. For the time being we put forward the hypothesis of the Dzyaloshinskii-Moriya coupling $\mathbf{D}$.[S $\mathrm{X} \mathbf{M}]$ where $S$ stands for $G_{z}(C r)$ and $M$ for $C_{y}(H o)$. The vector $D$ would be along $O x$.

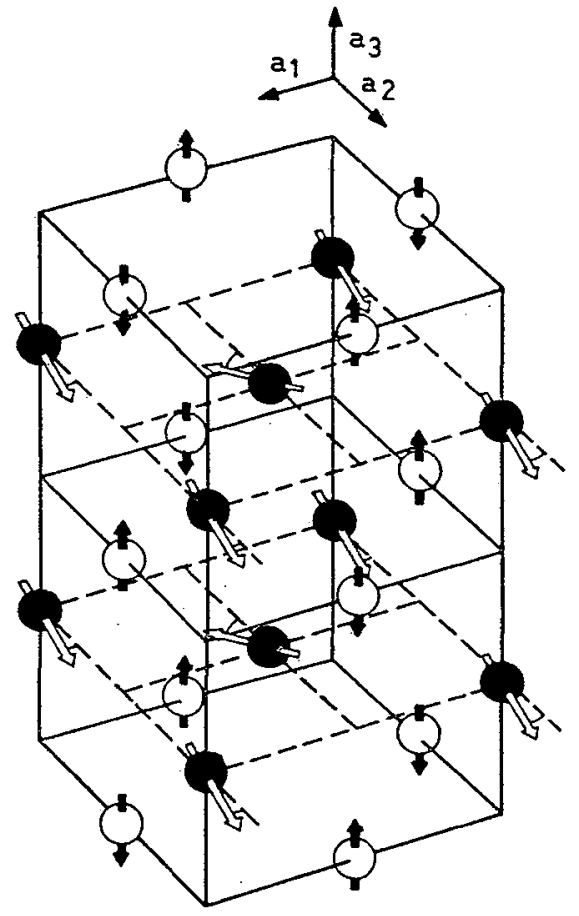

Fig. 3

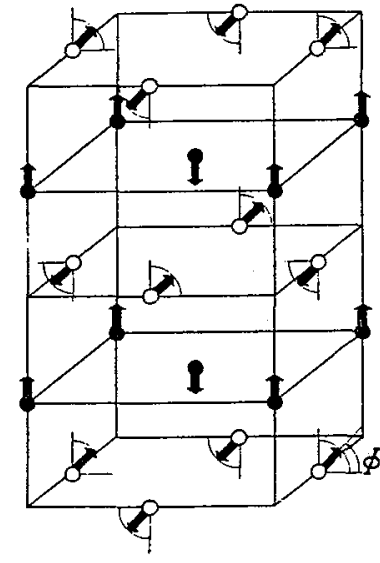

Fig. 4

Figure 3: Magnetic structure at low temperature : rare earth (full circle) : $\mathrm{Fe}, \mathrm{Cr}$ (empty circle). 3) $\mathrm{Phase}_{2} \mathrm{HoFeO}_{3} ; \mathrm{HoCrO}_{3}$; the rare earth moment is in the plane $\mathbf{a}_{1}, \mathbf{a}_{2}$

Figure 4: Magnetic structure at low temperature: $3 \mathrm{~b}$ ) Phase $\Gamma_{1}+\Gamma_{4} \mathrm{ErFeO}_{3}$; the rare earth moment is along $\mathbf{a}_{3}$.

Our second example for A-B coupling is $\mathrm{ErCrO}_{3}$ where at $\mathrm{T}_{\mathrm{N1}}=133.2 \mathrm{~K}$ the $\mathrm{Cr}$-moments order in the $\mathrm{G}_{\mathrm{X}} \mathrm{F}_{\mathrm{Z}}\left(\boldsymbol{\Gamma}_{4}\right)$ mode. Below $\mathrm{T}_{\mathrm{N} 2}=9.8 \mathrm{~K}$, neutron diffraction on powders established the existence of a $\mathrm{C}_{z}$ mode of Er coupled to a $\mathrm{G}_{\mathrm{y}}$ mode of $\mathrm{Cr}$ in $\Gamma_{1}$ (Bertaut et al. 1963). Single crystal studies by magnetization, specific heat measurments (Eibschütz et al. 1970) and optical spectroscopy (Courths et al. 1970) prove the nature of first order transition at $\mathrm{T}_{\mathrm{N} 2}=9.8 \mathrm{~K}$ and also that below $\mathrm{T}_{\mathrm{N} 2}$ the magnetization $F_{z}$ of $\Gamma_{4}$ has disappeared. Here too we infer a D-M coupling with $S$ for $G_{y}(C r), M$ for $C_{z}(E r)$ and $D$ along Ox.

The argument I put forward is that vector $\mathbf{D}$ depends on spin-orbit coupling and therefore on the existence of orbital moments $\mathrm{L}$ which have the high values $\mathrm{L}=6$ for $\mathrm{Ho}$ and for $\mathrm{Er}$. $\mathrm{ErCrO}_{3}$ and $\mathrm{HoCrO}_{3}$ have rather high temperatures for rare earth ordering $\mathrm{T}_{\mathrm{N} 2}=9.8 \mathrm{~K}$ and $12 \mathrm{~K}$ respectively. In $\mathrm{GdFeO}_{3}$ the orbital moment of $\mathrm{Gd}$ is zero and we expect a low temperature transition for the Gd-Fe ordering which indeed takes place at $\mathrm{T}_{\mathrm{N} 2}=1.47 \mathrm{~K}$ (Cashion et al. 1970).

Comparison with $\mathrm{ErFeO}_{3}$.- The $\mathrm{Fe}$ spins which just below $\mathrm{T}_{\mathrm{N}}$ are in the $\mathrm{G}_{\mathbf{x}} \mathrm{F}_{\mathrm{z}}\left(\Gamma_{4}\right)$ mode reorient to $F_{x} G_{z}\left(\Gamma_{2}\right)$ mode (Gorodetsky et al. 1973) continuously in the temperature interval 
$100-90 \mathrm{~K}$. The low temperature configuration of $\mathrm{ErFeO}_{3}$ comprises the $\mathrm{F}_{\mathrm{X}} \mathrm{G}_{\mathrm{Z}}$ mode of iron in the representation $\Gamma_{2}$ plus the modes $G_{y}$ of iron coupled to the mode $C_{z}$ of erbium in the representation $\Gamma_{1}$ (cf. Fig 4). The magnetic space group is the intersection of $\Gamma_{1}$ and $\Gamma_{2}$, say $21 x^{/ m}$ (Cracknell 1974).

Our last example is $\mathrm{TbFeO} 3$ where $\mathrm{Fe}^{3+}$ orders again in the $\mathrm{G}_{\mathrm{X}} \mathrm{F}_{\mathrm{Z}}$ mode of $\Gamma_{4}$ at $\mathrm{T}_{\mathrm{N} 1}=681 \mathrm{~K}$. Below and at $\mathrm{T}_{\mathrm{N} 2}=8.4 \mathrm{~K}$ one observes the same magnetic structure as described above for $\mathrm{HoCrO}_{3}$ and $\mathrm{HoFeO}_{3}$, say a $\mathrm{F}_{\mathrm{X}} \mathrm{G}_{\mathrm{Z}}$ mode on $\mathrm{Fe}$ coupled with $\mathrm{F}_{\mathrm{x}} \mathrm{C}_{\mathrm{y}}$ on $\mathrm{Tb}$. Lowering the temperature once more below $\mathrm{T}_{\mathrm{N} 3}=3.1 \mathrm{~K}$ one finds a $\mathrm{A}_{\mathrm{X}} \mathrm{G}_{\mathrm{y}}$ configuration in $\mathrm{Tb}$, but cannot decide between $G_{X}$ or $G_{Z}$ mode on the Fe site (Bertaut et al. 1967).

Actually in $\mathrm{TbCoO}_{3}$ where $\mathrm{Co}^{3+}$ is in the low spin state, $\mathrm{Tb}$ orders in the $\mathrm{A}_{\mathrm{x}} \mathrm{G}_{\mathrm{y}}$ configuration at $\mathrm{T}_{\mathrm{N}}=3.31 \mathrm{~K}$ (Maréschal et al. 1968). The conclusion was then that in $\mathrm{TbFeO}_{3}$ the magnetic orders of $\mathrm{Fe}^{3+}$ and $\mathrm{Tb}^{3+}$ were "decoupled". In fact one must be more prudent. If $F e$ is in the $G_{x}$ mode of $\Gamma_{4}$ and $T b$ in the $\Gamma_{8}$ mode, the magnetic space group, common to $\Gamma_{4}$ and $\Gamma_{8}$ is the non centrosymmetric group $\mathrm{P} 2_{1} 2_{1}^{\prime} 2_{1}$ in which $\mathrm{Fe}$ and $\mathrm{Tb}$ would remain coupled, provided that by a small displacement, Fe looses its inversion centre.

Representation analysis is not restricted to magnetism and can be applied to ferroelectricity with the only difference that the basis vectors are polar (Bertaut 1968b).

A final application of interest is the field of magnetoelectricity, abridged ME. The phenomenon was foreseen by $P$. Curie one century ago, predicted by Dzyaloshinskii (1960) to occur in $\mathrm{Cr}_{2} \mathrm{O}_{3}$ and measured first by Astrov (1960). The example considered here is $\mathrm{Fe}_{1.15} \mathrm{Ge}_{0.85} \mathrm{O}_{3}$, space group $\mathrm{Pc} 21 \mathrm{n}$. ME was seen there first by Rado (1964). The crystallographic structure was solved by Abrahams et al. (1965). The Grenoble team added the knowledge of the magnetic structure and space group $\mathrm{Pc}^{\prime} 2_{1}^{\prime} \mathrm{n}$ (Bertaut et al. 1965,1966). Delapalme (1968), using polarized neutrons, measured with a good precision the percentages of iron on the three octahedral sites and also on the tetrahedral site where Ga predominates.

$$
\begin{aligned}
& \text { Pc'2in } \text { Pc2 }_{1} n \\
& \text { AXIAL POLAR } \\
& \text { VECTORS } \\
& \begin{array}{lllllllll} 
& & x & z & & x & y & z \\
\Gamma_{1}(++) & C & G & F & & A & F & G \\
\Gamma_{2}(+-) & F & A & C & & G & C & A \\
\Gamma_{3}(-+) & A & F & G & & C & G & F \\
\Gamma_{4(--)} & G & C & A & F & A & C
\end{array} \\
& \mathrm{Fe}_{1.15} \mathrm{Ga}_{0.85} \mathrm{O}_{3} ; \mathrm{Pc}^{\prime} 2_{1}{ }^{\prime} \mathrm{n}
\end{aligned}
$$

Table 3 : Axial and polar basis vectors. 
In table 3, under the headings $\mathrm{Pc}^{\prime} 2_{1}^{\prime} \mathrm{n}$ and $\mathrm{Pc}_{1} \mathrm{n}$, one finds respectively the axial and the polar basis vectors. The product $F_{z}$ (axial) $F_{y}$ (polar) in the identity representation $\Gamma_{1}$ corresponds to the ME observed by Rado: a magnetic field $H$ applied in the direction $\mathrm{Oz}$ induces a magnetic moment $\mathrm{F}_{\mathrm{z}}$ and one measures an electric moment $\mathrm{F}_{\mathrm{y}}$ in the direction Oy. Reciprocally one may also apply an electric field $\mathrm{E}$ in the direction $\mathrm{Oy}$, induce an electric moment $\mathrm{F}_{\mathrm{y}}$ and measure the magnetic moment $\mathrm{F}_{\mathrm{z}}$. The two methods are abridged $(\mathrm{ME})_{\mathrm{H}}$ and $(\mathrm{ME})_{\mathrm{E}}$.

More generally if $\alpha \mathrm{ij}$ represents the ME tensor, one has in conventional notations

$$
\alpha_{i j} \cdot \delta H_{j}=\delta P_{i} \quad \text { and } \quad \alpha_{i j} \cdot \delta E_{i}=\delta M_{j}
$$

Here, $M_{j}$ and $P_{i}$ are the magnetic and electric moments. $M$ stands for $F$ (axial) and $P$ for $F$ (polar).

In $\mathrm{Fe}_{\mathrm{x}} \mathrm{Ga}_{2-\mathrm{x}} \mathrm{O}_{3}, \alpha_{\mathrm{yz}}$ is observed. One easily checks from table 3 that only $\alpha_{\mathrm{yz}}$ and $\alpha_{\mathrm{zy}}$ differ from zero. The main conclusion is that the knowledge of the magnetic and of the cristallographic structure allows the construction of the magnetoelectric tensor $\alpha_{\mathrm{ij}}$ with the only help of the basis vectors, axial and polar.

Recently the crystallographic structure of $\mathrm{FeAlO}_{3}$ has been investigated and described in space group Pna2 1 which is equivalent to $\mathrm{Pc} 2{ }_{1} \mathrm{n}$. It is isomorphous to $\mathrm{FeGaO}_{3}$ piezo-electric, ferrimagnetic and magnetoelectric (cf. Bourée et al. 1966 and references there in).

I have predicted magnetoelectricity to occur in $\mathrm{FeNaO}_{2}-\beta$ (Bertaut $1968 \mathrm{~b}$ ), also crystallising in Pna2 1 , but having the magnetic space group Pn'a2' (Bertaut et al. 1963); here $\alpha_{z y}$ and $\alpha_{x z}$ differ from zero. The Néel temperature is exceptionally high $\mathrm{T}_{\mathrm{N}}=723 \mathrm{~K}$, compared to $\mathrm{T}_{\mathrm{N}} \approx 310 \mathrm{~K}$ in $\mathrm{Cr}_{2} \mathrm{O}_{3}$ and in $\mathrm{Fe}_{1.15} \mathrm{Ga}_{0.85} \mathrm{O}_{3}$.

The Néel temperatures are much lower in compounds with bivalent transition metal compounds like the olivine type structure $\mathrm{LiCoPO}_{4}, \mathrm{~T}_{\mathrm{N}}=23 \mathrm{~K}$, space group Pnma which again is ME (Mercier et al. 1967).

In rare earth compounds like $\mathrm{TbAlO}_{3}$, the Néel température is very low $\left(\mathrm{T}_{\mathrm{N}}=3.9 \mathrm{~K}\right.$ ) but one has the satisfaction of an ME-effect ten times stronger than in $\mathrm{Cr}_{2} \mathrm{O}_{3}$ (Mercier et al. 1968). It is interesting to note that the $\mathrm{ME}$-effect in $\mathrm{TbAlO} 3$ disappears when the applied magnetic field is high enough to provoke a spin-flip. RA shows indeed that $F$ (axial) and $F$ (polar) are no longer found in the same representation. Similarly, there is no $\mathrm{ME}$ on $\mathrm{Fe}$ in the rare-earth iron oxides. Here, the axial vectors are in the representation $\Gamma_{1}$ to $\Gamma_{4}$ and the polar vectors in those from $\Gamma_{5}$ to $\Gamma_{8}$ so that they have no representation in common. More generally there is no ME on centres of symmetry.

An application of RA to ME is found in the paper "ME in theory and experiment" (Bertaut et Mercier 1971) which also summarizes Mercier's thesis work.

\section{REPRESENTATION ANALYSIS AND GARNETS}

Representation analysis has been summarized and commented with favour by Cracknell (1974). My own opinion is that RA is not so widely used as it should be in magnetic structure research (Sivardière 1970). What are the objections?

"Basis vectors of irreductible representations form an essential part of RA" - which is true - "and they are not always easy to find". I have proposed a formula (Bertaut 1981) for creating the b.v.i.r. which is easier to handle than those found in text books on group theory. Another more serious objection is that "RA lacks a thermodynamical basis and neglects Landau's theory of second order transitions". I have considered this objection more explicitely in the reference cited (Bertaut 1981).

Here, I must say that RA is not a thermodynamic, but geometrical construction, that we are not yet able to predict a magnetic structure and its thermal evolution and also that the principal use of Landau's theory is to show that most phase transitions must be first order.

I shall consider here RA in the thermal evolution of the structures of terbium and erbium iron garnets.

\section{TbIG}

It is well known that in all rare earth-iron garnet above the compensation temperature $\mathrm{T}_{\mathrm{c}}$, all magnetic moments are along one axis [111] in a given domain, so that from the start there is a magnetic anisotropy in the structure.Still let us use representation theory in the cubic paramagnetic group Ia3d $\left(\mathrm{N}^{\circ} 230\right)$. 
The research team is composed of Tchéou, Bertaut, Delapalme, Sayetat, Fuess. Tchéou is preparing his thesis, Delapalme is the specialist of polarized neutrons, Sayetat measures lattice distorsions by X-rays, Fuess is interested in garnets. Neutron diffraction below $\mathrm{T}_{\mathrm{c}}$ shows the presence of two modes on $\mathrm{Tb}$, denoted $\mathrm{S}_{\|}$and $\mathrm{S}_{\perp}$, respectively parallel and orthogonal to [111]. RA in the cubic group gets an acceptable agreement with observed intensities, but needs two different three-dimensional representations of the cubic group, $\Gamma_{4 g}$ for $S_{\|}$and $\Gamma_{5 \mathrm{~g}}$ for $S_{\perp}$, the direction of $S_{\perp}$ being [1 $\overline{1} 0$ ] plus permutations. However Sayetat finds a rhombohedral splitting in the $X$-ray pattern of the high angle reflections $\{8,6,4\}$ and $\{10,4,0\}$. Thus $\mathrm{RA}$ continues in the rhombohedral space group $R \overline{3} c$ for two reasons. Firstly, $S_{\|}$and $S_{\perp}$ are found there in the same

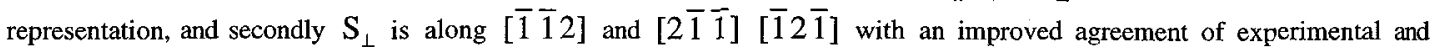
theoretical intensities.

The main conclusion is that the observed magnetic order does not belong to an irreducible representation of the paramagnetic group $\mathrm{Ia} \overline{3} \mathrm{~d}$, but to the magnetic group $\mathrm{R} \overline{3} \mathrm{c}^{\prime}$. Landau's theory of second order transitions does not apply to TbIG. The team cited above presented his results at the Rare Earth Conference, mai 1969 wich took place in Paris for the chemical part, in Grenoble for the physical part (cf. references cited Tchéou, Congress, and Solid State Comm. 1970). Their findings were confirmed and refined by Lahoubi et al. (1984).

However, there are no limits to progress. The famous powder instrument D2b of I.L.L. (which was conceived at the neutron diffraction laboratory of the CEN-G and constructed there (Roudaut)) had a higher resolution and a much lower background, divided by 40 in the $\{110\}$ region, and a new study was started by Hock, Fuess, Vogt, and Bonnet. Here Hock is the thesis student, Fuess the team leader, Vogt the I.L.L. representative, and Bonnet (CEN-G) is programming the RA according to the version Bertaut (1972). The reflections $\{200\}\{600\}\{422\}$ (in cubic notation) which are forbidden in $R \overline{3} c^{\prime}$ appear in the powder diagram. The space group is finally $R \overline{3}$ where a full refinement is made (Hock et al. 1990) whith significant changes in the atomic positions. More particularly one has $\mathrm{m}_{\perp}\left(\mathrm{Tb}_{1}\right) \neq \mathrm{m}_{\perp}\left(\mathrm{Tb}_{2}\right)$.

\section{ErIG}

The erbium iron garnet at low temperature $\left(4.2 \mathrm{~K}\right.$ ) was refined in space group $\mathbf{R} \overline{3} c^{\prime}$ (Tchéou et al. 1970) with results which seemed to be satisfactory; the two erbium moments turned out to be $m\left(\operatorname{Er}_{1}\right)=6.7 \pm 0.2 \mu_{\mathrm{B}}$ and $\mathrm{m}\left(\mathrm{Er}_{2}\right)=4.4 \pm 0.2$. About ten years later, Guillot et al. (1981a) had an unambiguous proof from magnetic measurments that at $4.2 \mathrm{~K}$ the easy direction of magnetization was [001]. A particularly elegant experiment is due to Antonini et al. 1981: A[110] disc of ErIG, allowed to rotate freely in a magnetic field, underwent an abrupt rotation at $73 \mathrm{~K} \pm 1.5 \mathrm{~K}$ by an angle of $54.7^{\circ}$ which is the angle between [111] and [001]. A specific heat anomaly was seen by Guillot et al. (1981b) at $\mathrm{T}=77 \pm 4 \mathrm{~K}$.

Finally, a new neutron diffraction study was launched by the same team as under TbIG (Hock et al.), and RA was applied to space group $I 4_{1} / \mathrm{acd}$, maximal subgroup of $\mathrm{Ia} \overline{3} \mathrm{~d}$. Among the 10 possible irreducible representations of $14_{1} / \mathrm{acd}$, listed in the book of Bradley and Cracknell (1972) only two, $\Gamma_{2 \mathrm{~g}}$ and $\Gamma_{5 \mathrm{~g}}$, couple Er and Fe moments. $\Gamma_{2 \mathrm{~g}}$ alone is convenient and corresponds to the magnetic group $\mathrm{I}_{1} / \mathrm{ac}^{\prime} \mathrm{d}^{\prime}$. Once more $\Gamma_{2} \mathrm{~g}$ does not belong to an irreducible representation of the paramagnetic group Ia $\overline{3} \mathrm{~d}$ and Landau's theory of second order transitions does not apply. The basis vectors of $\Gamma_{2} \mathrm{~g}$ are tabulated in the paper by Hock et al. 1991. Those of Fe in $8 \mathrm{a}$ are collinear and opposite along [001] with $\mathrm{S}_{\|}(\mathrm{Er})=7 \mu_{\mathrm{B}}$. Those of $\mathrm{Er}$ in $16 \mathrm{e}$ and $\mathrm{Fe}$ in $16 \mathrm{c}$ and $16 \mathrm{~d}$ participate in the ferri-magnetism along $\mathrm{Oz}$, but are allowed to have $\mathrm{m}_{\perp}$ components, forming anti-ferromagnetic arrays.

The refinement from the powder diagram resulted in $m_{\|}(E r)=4 \mu_{B} \quad m_{\perp}=1.7 \mu_{B}$ for $\operatorname{Er}(16 \mathrm{e})$; for the iron moments only $\mathrm{m}_{\|}$ could be refined with $m_{\|}$nearer to 4 than to $5 \mu_{\mathrm{B}}$.

The most spectacular and direct proof for the first order transition of the spin reorientation from [111] to [001] was established by Hock et al. (1992) using X-ray and neutron topography and vizualising the coexistence of the rhombohedral and tetragonal phases of ErIG in the temperature interval $73<\mathrm{T}<79$.

In the garnet case, $I$ conclude that the moments $m_{\|}$follow from the superexchange mechanism of ferrimagnetism. The moments $\mathrm{m}_{\perp}$ are mainly due to the antisymmetric $\mathrm{D}$-M interaction. I hope that studies with single crystals will continue.

\section{REFERENCES}

\section{Néel Message}

ALEONARD R., PAUTHENET R., BARBIER J.C. 1956 Comptes Rendus 242 p.2531.

BERTAUT E.F. 1950 Comptes Rendus $\underline{230}$ p.213 et errata 231 p.88.

KRAMERS H.A. 1934 Physica 1 p.182. 
NÉEL L. 1932 Doctor thesis, reprinted in Oeuvres scientifiques de L. Néel, Éditions du CNRS 1978, A7 p.3-27; 1948 Ann. de Phys. $\underline{3}$ p.137-198 and ibid. A61, pp.73-103

SMART J.S. 1963 Magnetism Vol.III p.63-114 (Rado and Suhl, Academic Press).

SRIVASTAVA C.M., SRINIVARAN C., AIYAR R 1982 J. Appl. Phys. $\underline{53}$ p.781-782.

VERWEY E.J.W., HEILMANN E.L. 1947 J. Chem. Phys. 15 p.147.

WEIS P. 1950 Comptes Rendus $\underline{143}$ p. 1137.

\section{On Sulfides}

BERTAUT E.F. 1952 Comptes Rendus 234, 1295; 1953 Acta Cryst. 6, 557; 1956 Bull. Soc. Fr. Min. Crist. 79, 276-292; 1979 Pure. and Appl. Cem. 52, 73-92.

BERTAUT E.F., BURLET P. and CHAPPERT 1965 Solid State Comm 3 , 336.

COEY J.M.D., SPENDER M.R, and MORRISH 1970 Solid State Comm. 8, 1605-1608.

EVANS H.T. Geochimica and Cosmochimia Acta : Proceedings of the Appolo 11, Lunar Science conference 1, 399-408

GOODENOUGH J.B. 1962 J.Appl. Pys., Supplement 33, 1197-1199; 1982 Ann. Chim. Fr. 7, 489-504.

HARALDSEN H. 1941 Z.Anorg. Allg. Chemie 246, 169.

HIRONE T., MAEDA S. and TSUYA 1954 J. Phys. Soc. Japan 9, 503.

KING H.E. and PREWITT C.T. 1982 Acta Cryst. B38, 1877-1887.

PUTNIS A. 1974 Science $\underline{186}, 439-440$.

TÖPEL-SCHADT J. and MÜLLER W.F. 1982 Phys. Chem. Minerals $\underline{8}, 175-179$.

WINTENBERGER M., SROUR B., MEYER C., HARTMANN-BOUTRON F. et GROS Y. 1978a; J. de Physique 39, 965 979.

WINTENBERGER M. and BUEVOZ J.L. 1978b Solid State Comm. 27, 511-513.

\section{Representation analysis}

ASTROV D.N. 1960 JETP 11708.

BERTAUT E.F. 1961 J. Phys. Chem. Solids 21 256-279;

1962 J. Phys. Rad. 23 460-465;

1963 Treatise on Magnetism Vol III, Chapter 4 (Rado and Suhl), Acad. Press. N.Y.;

1966 Ztschr. f. Angew. Physik 21 259-268;

1966 Internationale Konferenz Magnetismus, 13-15 octobre, DRESDEN, GERMANY, Magnetismus, VEB, Leipzig (1967) p.35-47;

1968a Acta Cryst. 24 217-231;

1968b Helv. Phys. Acta 41 688-692;

1971 J. Phys. 32 462-470. Colloque Cr;

1972 Ann. de Phys. $7203-232$;

1973 Vol. Magnetism, Chap. 6 211-231 Gordon and Breach, ed. Haidemanakis, Proceedings of Summer School 1969 , Creta, Greece;

1981 J. Mag. Mag. Materials 24 267-278.

BERTAUT E.F., DELAPALME A., BASSI G. 1963 C.R. Ac.Sc. 257 421-424.

BERTAUT E.F., BUISSON G., CHAPPERT J., BASSI G. 1965 C.R. Ac.Sc. 260 3355-3358.

BERTAUT E.F., BASSI G., BUISSON G., CHAPPERT J., DELAPALME A., PAUTHENET R., REBOUILLAT J.P., ALÉONARD R. 1966 J. Phys. 27 433-448.

BERTAUT E.F., MARÉSCHAL J., DE VRIES G., ALÉONARD R., PAUTHENET R., REBOUILLAT J.P., ZARUBICKA 1966b IEEE Trans. on Magn. 2 43-49, INTERMAG CONF., april 20-22, 1966, Stuttgart, GERMANY. 
BERTAUT E.F., CHAPPERT J., MARÉSCHAL J., REBOULllAT J.P., SIVARDIÈRE J. 1967 Solid State Comm. $\underline{5}$ 293-298.

BERTAUT E.F., MERCIER M. 1971 Materials Res. Bull. $\underline{6}$ 907-922.

BOURÉE F., BAUDOUR J.L., ELBADRAOUI E., MUSSO J., LAURENT C. ROUSSET A. 1966 Acta Cryst B52 217222.

CASHION J.D., COOKE A.H., MARTIN D.M., WELLS M.R. 1970 J. Appl. Phys. 411193.

COURTS E., HÜFNER S., PELZL J., VAN UITERT L.G. 1970 Solid State Comm. 8 1163-1165.

CRACKNELL A.P. 1974 Advances in Physics 23 673-866.

EIBSCHÜTZ M., HOLMES L., MAITA J.P., VAN UITERT L.G. 1970 Solid State Comm. $\underline{8}$ 1815-1817.

GORODETSKY G., HORNREICH K.M., YAGER I., PINTO H., SHACHAR G., SHAKED H. 1973 Phys. Rev. B $\underline{8}$ 3398-340.

HASSON A., HORNREICH R.M., KOMET Y., WANKLYN B.M., YAEGER I. 1975 Phys. Rev.

B12 5051-5067.

HOLMES L., SHERWOOD R. and VAN UTTERT L.G. 1968 J. Appl. Phys. 39 1373-1374.

KOEHLER W.C., WOLLAN E.O., WILKINSON M.K. 1960 Phys. Rev. 11858.

MARÉSCHAL J., SIVARDIÈRE J., DE VRIES G., BERTAUT E.F. 1968 J. Appl. Phys. 39 1364-1366.

MERCIER M., GAREYTE J., BERTAUT E.F. 1967 C.R. Ac. Sc. 264 979-982.

MERCIER M., CURSAUX B. 1968 Solid State Comm. $\underline{6}$ 207-209.

NÉEL L. 1948 Ann. de Physique.

RADO G.T. 1964 Proceedings Int. conf. Magnetism, Nottingham 7-11 sept 1964, pp.361-366.

WIEGELMANN H., JANSEN A.G.M., WYDER P., RIVERA J-P., SCHMID H. 1994 Ferroelectrics 162 141-146.

WIEGELMANN H. 1995 Doctor thesis, Konstanz, GERMANY.

YAMAGUCHI T. 1974 J. Phys. Chem. Solids $\underline{35}$ 479-500.

\section{Representation analysis and garnets}

BERTAUT E.F. 1981 J. Mag. Mag. Materials 24 267-278.

BERTAUT E.F., SAYETAT F., TCHÉOU F. 1970 Solid State Comm. $\underline{8}$ 239-245.

BRADLEY C.J., CRACKNELL A.P. 1972 Oxford Clarendon Press. The mathematic theory of symmetry in solids.

GUILlOT M., MARCHAND A., TCHÉOU F., FELDMANN P., LE GALL H. 1981a Z. Phys. B - Condensed Matter 44 41.

GUILLOT M., TCHÉOU F., MARCHAND A., FELDMANN P., LAGNIER R. $1981 \mathrm{~b}$ Z. Phys. B - Condensed Matter 44 53.

HOCK R., FUESS H, VOGT T., BONNET M. 1990 J.Solid State Chem. Phys. $\underline{84}$ 39-51. ibid. 1991 Z. Phys. B Condensed Matter $\underline{82}$ 283-294.

HOCK R., BARUCHEL J., FUESS H., ANTONINI B., PARDI P. 1992 J. of Magn. Magn. Mat. 104-107 453-455.

SIVARDIÈRE J. 1970 Acta Cryst. A26 101-105

TCHÉOU F., BERTAUT E.F., SAYETAT F., DELAPALME A., FUESS H.1970a International Conference on Rare Earths (mai 1969) vol II p.313-332, Congrès CNRS N'180.

TCHÉOU F., BERTAUT E.F., FUESS H. 1970b Solid State Comm. $\underline{8}$ 1751-1758. 


\section{THE STORY OF THE GARNETS}

The story starts with the perovskites $\mathrm{MRO}_{3}$, where $\mathrm{M}$ is a transition metal and $\mathrm{R}$ a rare earth. In 1953 I got a Fullbright fellowship and spent the major part of the year at State College, Pa.,USA (now University Park) in the laboratory of Prof. Ray PEPINSKY, engaged in a project on ferroelectricity.

There I met his coworkers Franco JONA and Gen SHIRANE, specialists of ferroelectricity (1962). At this period, Chalmers FRAZER, another coworker of R. Pepinsky did neutron work at the Brookhaven National Laboratories on the ferroelectric transitions of the famous perovskite $\mathrm{BaTiO}_{3}$ in order to determine the oxygen displacements. After returning from the States, I launched a rather ambitious program for preparing $\mathrm{MRO}_{3}$ compounds with $\mathrm{M}=\mathrm{Ti}, \mathrm{V}, \mathrm{Cr}, \mathrm{Mn}, \mathrm{Fe}$, Co and for $\mathrm{R}$ those rare earths which were available, say the lighter ones called « ceric », Ce, Pr, Nd, Sm, Gd. My thesis student Francis FORRAT prepared them with the help of our chemist, Claudine MOESCH, by the method usual in our laboratory: dissolution of the oxides separately in nitric acid, mixture, evaporation of the nitric acid followed by heating the powder to temperature between 1100 and $1400^{\circ} \mathrm{C}$. We had the secret hope to find new structures with interesting dielectric properties.

We knew about magnetic measurements on compounds labelled $« \mathrm{RFeO}_{3} »$, which has the strange property of showing two Curie-temperatures (FORESTIER and GUIOT-GULLLAN (1950-1954)) and even a third critical temperature where the magnetisation changed its sign (FORESTIER, PAUTHENET and GUIOT-GUILLAIN (1954), PAUTHENET and BLUM (1954)).

To interpret these results, NEEL (1954) made the hypothesis of a ferrimagnetism acting on the rare earth.

On our side some powder diagrams like that already known of $\mathrm{LaCoO}_{3}$ were easily indexed in the rhombohedral system. But in most cases, we were unable to find the unit cell and cumulated lists of $\sin ^{2} \Theta$ of $\mathrm{MRO}_{3}$ compounds.

One day, end of 1954, Nẻel got the visit of Bernd MATTHAS, well known specialist in ferroelectricity and superconductivity of alloys, then at the Bell Laboratories; Matthias learnt about the rare earth-ferrites problems and promised to send a single crystal of $\mathrm{GdFeO}_{3}$, convinced that J.P. REMEIKA, specialist of crystal growth could solve the problem. After a long while, Professor Néel got such a crystal and in a short time we could determine the unit cell, the space group Pbnm, the positions of the four Fe atoms, located at symmetry centres and a good approximation for the Gd locations in the deformed perovskite type.

We summarized the unit cells and space groups of about forty compounds $\mathrm{MRO}_{3}$ in a paper by Bertaut and Forrat (1956b) « Sur les déformations dans les pérovskites à base de terres rares et d'éléments de transition trivalents ». We also learnt that the structure of $\mathrm{GdFeO}_{3}$ had been already solved at Bell Labs (Geller 1955, 1956) and included this information in our paper, published in february 1956.

For us, the important point was the following one: we realized at once that iron in equivalent symmetry centres could not give rise to ferrimagnetism, but at most to a weak ferromagnetism comparable to that of $\alpha-\mathrm{Fe}_{2} \mathrm{O}_{3}$, which was soon confirmed by Pauthenet's measurements given in his thesis (1957, 1958).

Thus we looked systematically for the « ferrimagnetic impurity ». Increasing the proportion of $\mathrm{Fe}_{2} \mathrm{O}_{3}$, we saw in our DebyeScherrer diagram the progressive fading of the many perovskite reflections and the appearance of a very simple pattern of Debye-Scherrer lines which could be indexed in the body-centerd cubic system and started with the relatively high indices $1,1,2$. The many extinctions clearly indicated the last space group of the International Tables $\mathrm{N}^{\circ} 230, I a 3 d$ which assigns the parameterless positions $16 \mathrm{a}, 24 \mathrm{c}$ and $24 \mathrm{~d}$ to the cation's positions which are compatible with the proportions of iron and rare earth in the sample. The corresponding site symmetries are 3,222 and 4.

As for each distance $d(\mathrm{ac})$ one finds an equal distance $\mathrm{d}(\mathrm{ad})$, we hesitated between two models, model I with Fe in $24 \mathrm{~d})$ and $R$ in $24 c$ ) and model II with the 24 fold positions interchanged, until we discovered that we had to do with garnets like $\mathrm{Al}_{2}\left(\mathrm{CaSiO}_{4}\right)_{3}$ (MENZER, 1928) realizing the substitutions

$\mathrm{Ca}^{2+}+\mathrm{Si}^{4+} \rightarrow \mathrm{R}^{3+}+\mathrm{Fe}^{3+}, \quad \mathrm{Al}^{3+} \rightarrow \mathrm{Fe}^{3+}$

$24 \mathrm{c} 24 \mathrm{~d} \quad 16 \mathrm{a}$

To summarize, $\mathrm{Fe}^{3+}$ is in the octohedral positions $16 \mathrm{a}$ and the tetrahedral positions $24 \mathrm{~d}$ while $\mathrm{R}$ is in the positions $24 \mathrm{c}$, centres of highly deformed cubes.

From Felix TROMBE, famous specialist of rare earth chemistry - discoverer of the ferromagnetism of Gd and EuO - and also father of the solar furnace of ODEILLO, we had got very pure oxides of Gd and in decreasing order of weight of Sm, Dy, Er and also of Y.

A detail, amusing today, but rather deceiving in 1956 , was that thefirst rare earth-iron garnet syntesised, $3 \mathrm{Gd}_{2} \mathrm{O}_{3} .5 \mathrm{Fe}_{2} \mathrm{O}_{3}$, was only weakly ferimagnetic at room temperature, its compensation temperature being $290 \mathrm{~K}$ as we learnt later on. Our generator of magnetic fields was a little magnet of five grammes.

However the strong action of the YIG sample confirmed our hopes. Our first paper on the iron gamets of the rare earths was written in november 1955. After some criticism and additonal remarks of Professor Néel, a second draft was ready in december 1955. The final note was presented by Prof. Charles MAUGUNN to the French Academy of Sciences, and appeared in print january 1956 (BERTAUT and FORRAT (1956 a)).

I got an enthousiastic letter of congratulation from Dr J.S. SMART, then «Liaison Officer of the U.S. Navy » in London, U.K., who propagated the news to the USA. I recall here that J.S. Smart is coauthor with C.G. SHULL of the first neutron diffraction study of $\mathrm{MnO}$ (1949) and that with Mrs GREENWALD he did pionneering work on the crystallographic deformations of transition metal oxides at the Néel temperature. 
R. PAUTHENET chose at once the rare earth-iron garnets - and our samples - as principal subject of bis doctor thesis. With his colleagues ALEONARD and BARBIER (1956) CR. Acad. sci. (195, 242, 2531), he used Néel's formula (13) to represent the inverse susceptibility of YIG, the ideal ferrimagnet, and to obtain reliable interaction coefficients.

Francis PERRIN, head of the French Atomic Energy Commission (CEA), Néel's colleague at the Institut de France, allowed us the use of the Research Reactor EL2 in Saclay during two days and two nights for recording the first neutron diffraction diagrams in France, those of YIG, which definitely established its ferrimagnetic nature (BERTAUT, FORRAT, HERPIN, MERIEL (1956), C.R. Acad. Sci. 243 (1956) 898-901).

In fact, two powder diagrams were recorded at room temperature.

The first one reproduced the nuclear and magnetic contributions. In the second diagram, a permanent magnet created a magnetic field parallel to the scattering vector, eliminating the magnetic contributions. The difference diagram showed only magnetic intensities in good agreement with the theoretical prediction of the ten measured intensities.

Finally we completed our papers on cell dimensions of rare earth orthoferrites $\mathrm{RFeO}_{3}$ and iron garnets $3 \mathrm{R}_{2} \mathrm{O}_{3}, 5 \mathrm{Fe}_{2} \mathrm{O}_{3}(\mathrm{Bertaut}$ and Forrat $1956 \mathrm{a}, \mathrm{b}$ ) by those of gallates and aluminates (Bertaut and Forrat 1956 c, C.R. Acad. Sci. 243 (1956) 1219-1220) and showed that the parameter values of garnets are reproduced by linear relation (Bertaut and Forrat, C.R. Acad. Sci. 246 (1957) 96-98).

Pauthenet on his side examined the whole series of rare earth iron garnets from the experimental (1956 a) and theoretical (1956 b) point of view. These two papers summarize so to speak his thesis defended in january 1957 and printed in 1958. There he lists the inverse susceptiblities and the measured magnetisations and deals with he case of three sublattices.

As far as international meetings are concerned, there has been a presentation at the Magnetic Materials Conference, 23-31 march 1956, Moscow, by L. NEEL, F. BERTAUT, F. FORRAT and R. PAUTHENET with the title: « A new type of ferromagnetic substances, rare earth ferrites having the garnet type structure $»$. The paper appeared in Izvest. Akad. Nauk. SSSR MOSCOW (1957) 21904.

Pauthenet and myself got an invitation to the « Convention on Ferrites of the I.E.E. London 1956 ». On 31 octobre, I talked there about the crystallographic properties of the ferrimagnetic garnets followed by Pauthenet, who treated their magnetic properties. Our contributions appeared in Proc. IEE (1957) 104B suppl. N 5 , 261-264. This paper had the privilege of being reprinted in the volume I of " Selected Papers in Physics (1950-1957) » of the Physical Society of Japan.

These lines are written to recall that the rare earth- and yttrium-iron garnets have been described and characterized crystallographically and magnetically in one year, from january 1956 to january 1957 , and there was no need to rediscover them in other countries.

ALEONARD, R., PAUTHEHET, R., and BARBIER, J.C., 1956, C.R. Acad. Sci. (Paris) 242, 2531-2533.

Propriétés magnétiques du ferrite d'yttrium $5 \mathrm{Fe}_{2} \mathrm{O}_{3} \cdot 3 \mathrm{Y}_{2} \mathrm{O}_{3}$.

BERTAUT, $F$. and FORRAT, F.

1956 a, C.R. Acad.Sci. (Paris) $242,382-383$

Structure des ferrites ferrimagnétiques des terres rares.

1956 b, J. de Physique et du Radium, 17, 129-131

Sur les déformations dans les pérovskites à base de terres rares et d'éléments de transition trivalents.

1956 c, C.R. Acad. Sci. 243, 1219-1222

Etude des combinaisons des oxydes des terres rares avec l'alumine et la galline.

1957, C.R. Acad. Sci. 244, 96-98

Etude des paramètres des grenats.

BERTAUT, F. and PAUTHENET, R., (1957) Proceedings of the I.E.E. Convention on Ferrites, London, 31 Oct. 1956 Crystalline structure and magnetic properties of the Garnets: $5 \mathrm{Fe}_{2} \mathrm{O}_{3}, 3 \mathrm{M}_{2} \mathrm{O}_{3}$ with $\mathrm{M}=\mathrm{Y}, \mathrm{Gd}, \mathrm{Tb}, \mathrm{Dy}, \mathrm{Ho}, \mathrm{Er}, \mathrm{Tm}, \mathrm{Tb}, \mathrm{Lu}$.

FORESTIER, H. and GUIOT-GULLLAIN, G. (1950) C.R. Acad. Sci., 239, 155-157

Etude thermomagnétique des ferrites de dysprosium et d'erbium.

GELLER, S. (1955) Phys. Rev., 99, 1645; (1956) J. Chem. Phys., 24, 1236-1239

Crystal structure of gadolinium orthoferrite.

GREENWALD, S. and SMART, J. S., (1950) Nature 166, 523

Lattice distorsion in $\mathrm{MnO}, \mathrm{FeO}, \mathrm{CoO}$.

GUIOT-GUILLAIN, G., PAUTHENET, R., FORESTIER, H. (1954) C.R. Acad. Sci. 239, 155-157

Etude thermomagnétique des ferrites de dysprosium et d'erbium.

JONA, F. and SHIRANE, G. (Monographs on Solid State Physics) , Pergamon, 1962

Ferroelectric Crystals. 
MENZER, G., (1928) Ztschr. f. Krist.

Die Kristallstruktur des Grossularits $\mathrm{Ca}_{2} \mathrm{Al}_{3}\left(\mathrm{SiO}_{4}\right)_{3}$

NEEL, L., BERTAUT, F., FORRAT, R. and PAUTHENET, R., (1957) Izvet Akad. Nauk. SSSR, 21, 904, N $^{\circ} 6$ Conf. Magn. Materails, Moscow, 21-31 march 1956

A new type of ferromagnetic substances: rare earth ferrites having the garnet type structure .

PAUTHENET, $R$.

1956 a: C.R. Acad. Sci. 243, 1499-1502

Propriétés magnétiques de ferrites de terres rares $5 \mathrm{Fe}_{2} \mathrm{O}_{3}, 3 \mathrm{M}_{2} \mathrm{O}_{3}$

1956 b: C.R. Cad. Sci. 243, 1737-1740

Interprétation des propriétés magnétiques des ferrites $5 \mathrm{Fe}_{2} \mathrm{O}_{3}, 3 \mathrm{M}_{2} \mathrm{O}_{3}$

PAUTHENET, R. and BLUM, P. (1954) C.R. Acad. Sci. 239, 33-35

Etude thermomagnétique du ferrite de gadolinium

SHULL, C. and SMART, J.S., 1949, Phys. Rev. 76, 1256 